wald's contention that the basis of harmony is equality of spacing; when, however, we compare the marks allotted to the equally spaced combina. tions with those that show a moderate inequality we find no further confirmation of the claim. As for the claim that membership of the same circle is a condition favouring harmony, the evidence at our disposal points, if anything, the other way.

Since no amount of inspection enabled $m e$ to discern the nature of the second factor, I decided to carry out a second test removing the four greyed combinations and the three least popular of the unequally spaced combinations. I then asked a dozen people (ten of whom had done the previous test) to range the remaining seventeen combinations by linear method. The results brought to light a truly dominating bipolar factor. Inspection of the items most diversely judged reveals two characters that it is easier to perceive than name. Some idea of the characters may possibly be indicated by pointing out that the leading members of one set each contained a pale green and a pale red, while those of the other set contained orange-yellows and deep greens. What is of special psychological interest is that no trace of this factor can be seen in the results of the original test, in which, of course, all the seventeen items were included. It appears that before these characters could be attended to, other more striking qualities such as greyedness and wide inequality of interval had to be eliminated. Once this has been done, these characters carry all before them.

In these tests of triple combinations, the three terms in each item were made to cover equal areas. This, of course, made it improbable that anything like the most pleasing combinations were reached. To achieve this result many more experiments would be necessary, and I hope in due time to carry these out. But the relative unpleasantness of the items in the tests so far done has not made it impossible to discern some of the principles influencing subjects in their assessment of the relative merits of colour combinations. What stands out with especial clearness is the complexity of the problem of colour harmony ; any attempt, like Ostwald's, to explain it by a single principle seems foredoomed to failure.

\title{
THE BONE-BEARING BEDS OF BETHLEHEM
}

$\mathrm{T}$ HE excavation of the bone-bearing beds of Bethlehem was undertaken by the Wellcome Archæological Expedition to the Near East under the auspices of the Department of Antiquities, Palestine, and work was carried on for three seasons (1935-7) with E. W. Gardner as geologist and D. M. A. Bate as palæontologist. The continuation of the work in 1937 was made possible through the support of the trustees of the late Sir Henry Wellcome, and of the late Sir Robert Mond. A preliminary account of the results was published in NATURE of September 4, 1937.

No work was done on the site in 1938 or 1939 , but last year (1940) the co-operation of Dr. Stekelis of the Hebrew University was enlisted to complete the excavation so far as possible. His report has now been received and shows that some notable results have been achieved. In the area from which specimens had already been obtained, work was continued to a depth of several metres below the last occurrence of animal remains, but it was not possible to test the horizontal extent of the bone bed. The geological and archæological finds do not seem to provide very definite or final evidence regarding the history, or the possible human occupation of the site, but an interesting suggestion is made by Dr. Stekelis that a

number of split bones collected may have been worked by man. A detailed study and comparison of these specimens should prove of exceptional interest.

A considerable quantity of animal remains was obtained, and the specimens will be sent in due course to the British Museum (Natural History) for study and description, together with those of the earlier collections. Dr. Stekelis's list shows that at least six species are recognized; they are as follows:

Bos sp.

Antelope

Equus sp. (? Hipparion)

A number of valuable specimens were recovered and these include a mandibular ramus with teeth, and an almost complete skull with cheek teeth of Rhinoceros ; Elephas or Stegodon is represented by a ramus with molars, as well as by isolated teeth and limb bones. Portions of jaws with teeth of antelope, and various remains of ox are also present. All these should be of value not only for determining the species, but also in interpreting the geological age and the relationship and status of this very interesting fossil fauna.

D. M. A. B.

\section{VELOCITIES OF EARTHQUAKE WAVES}

$\mathrm{F}^{\mathrm{n}}$ RANCIS BIRCH has published a paper entitled "The Variation of Seismic Velocities within a Simplified Earth Model, in accordance with the Theory of Finite Strain" (Paper 55, Geophysical Research, Harvard University), which marks a somewhat new direction for seismological research.

The author states that the treatment of many problems concerning the elasticity of the earth as a whole has been handicapped by the lack of an adequate theory of finite deformation, which would permit quantitative estimation of the effects of the initial strain of the material below the surface. While certain artifices which have been employed to evade this difficulty have had the merit of adding a sufficient number of conditions to allow the solution of various special problems, they have proved 